\title{
Active Control of Cryogenic Propellants in Space
}

\author{
W.U. Notardonato ${ }^{1}$

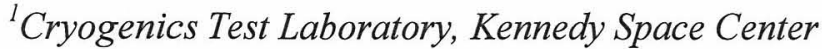

\begin{abstract}
A new era of space exploration is being planned. Exploration architectures under consideration require the long term storage of cryogenic propellants in space. This requires development of active control systems to mitigate the effect of heat leak. This work summarizes current state of the art, proposes operational design strategies and presents options for future architectures. Scaling and integration of active systems will be estimated. Ideal long range spacecraft systems will be proposed with Exploration architecture benefits considered.
\end{abstract}

\section{INTRODUCTION}

With the retirement of the Space Shuttle fleet and the cancellation of the Constellation program, a new era or human space exploration in the Unites States is dawning. But there is much uncertainty regarding the future direction of space exploration in the United States. This uncertainty is extensive and includes the role of the commercial enterprises in manned launches to low earth orbit (LEO), the near term destination of manned exploration, and the type and size the future space launch systems. However, it is certain that near-term human exploration beyond low earth orbit will require the use of cryogenic propellants, and that in-space cryogenic propellant storage durations will exceed our current capabilities by two or more orders of magnitude. This will require development and validation of a new suite of technologies, from large scale insulation systems to microgravity fluid control to active thermal control of cryogens for extended duration zero boil off. Cryogenic fluid management technology may enable deployment of orbital propellant depots, and these propellant depots may dramatically lower the cost of human exploration beyond LEO. This work will consider the current state of the art in cryogenic operation in space and will propose operational design principles to use as a guideline for developing space exploration architectures. These principles will be used to develop a reference propellant depot architecture. This is not an approved mission architecture that has been vetted by NASA and should be considered to be for discussion purpose only.

\section{CRYOGENIC DEPOT DESIGN PRINCIPLES}

The advantages of cryogenic propellant depots in space have been discussed since early in the space program (ref). Werhner Von Braun used in space refueling as a components of his famous human exploration of space articles in Colliers magazines in the 1950's. Most early concepts called for large orbiting complexes requiring multiple launches to assemble the depot in orbit, followed by multiple resupply missions to transport large quantities of cryogens to the orbital storage complex. Depot customers then rendezvous with the station and purchase propellants in whatever quantities needed. This architecture is analogous to a terrestrial gas station, where semi-permanent facilities are built to provide a range of refueling capabilities. The scale and complexity of these types of depots will probably prohibit their deployment for the near future, until launch costs are decreased significantly. Other smaller depot studies have been performed over the years. More recently, Kutter et al have been proposing a simpler depot concept that uses a single launch to provide refueling capability to a single dedicated mission.ref). The Augustine committee report (ref) identified in space refueling as a "significant potential benefit to the in-space transportation system beyond low-Earth orbit", and considers both models of depots as feasible. However, perceived complexity and launch costs have helped limited the development of propellant depots, and critical technology demonstrations for microgravity handling of cryogens must be achieved before these concepts will gain acceptance by NASA mission planners. NASA is currently planning a technology demonstration mission that will prove many of the systems needed for long duration cryogenic storage in LEO, including active and passive thermal control, propellant acquisition and gauging, and cryogenic transfer between storage vessels. This work is an attempt to look at an in-space consumable depot from a perspective of operability Key principles to consider during design are maintaining simplicity, commonality and reliability in the system, and maximum reusability of hardware when possible. Active control of the propellant so there are no consumable losses are achievable

\subsection{Commonality}

To keep spacecraft more simple and to reduce resupply requirements for long term, sustainable human exploration, future architectures should minimize the different number of fluids on board the spacecraft. Minimizing the number of different commodities, especially hazardous commodities, has been identified as a top priority for operability for spacecraft systems (ref). Using common fluids reduces the overall parts count of the spacecraft fluid systems, reducing mass and complexity. Fluid needs include propulsion, power and life support. Almost all consumable needs can be met by delivery of one single fluid, water. Water, plus its individual components of hydrogen and oxygen, can meet all the requirements of human exploration consumable supplies.

Propulsion - Liquid hydrogen and liquid oxygen are already in use for primary in space propulsion applications, and exhibit the highest performance of any practical chemical propellant combination. LOX/LH2 engines such as the RL-10 and J2-X are considered the likely choices for future exploration propulsion needs. Future advanced primary propulsion needs can also be met using hydrogen, as hydrogen can be used for nuclear thermal and solar electric propulsion as well. Additionally, spacecraft designers need to consider hydrogen and oxygen as ideal candidates for secondary propulsion as well. Hypergols are currently the first choice of designers due to their storability, reliability, and long history of successful use. But advances in active and passive thermal control will enable long 
duration cryogenic storage, making these propellants essentially as "storable" in space as hypergols (which often requires heating as an active thermal control scheme for many mission profiles). Work is also ongoing at several companies to prove reliability of GOX/GH2 thrusters, and some units have demonstrated 10,000 successful ignition cycles. Use of common fluids for all propulsion needs will greatly simplify spacecraft design and operations.

Power - hydrogen and oxygen have been used as power reactants in fuel cell systems since the Gemini program. Fuel cell power will be needed to supplement solar power for future exploration missions, and regenerative fuel cell power is needed during nighttime at lunar bases. Fuel cells have a higher power density that batteries and will also be needed on rovers and other remote equipment. Until nuclear power and improved battery power is available, fuel cells will be part of the exploration architecture, and hydrogen and oxygen will be the necessary reactants. With the use of Proton Exchange Membrane fuel cells, ultra-high purity oxygen will not be needed, and propellant grade LOX and LH2 is sufficient.

Life support - Life support consumables include potable water for drinking, water for cleaning and bathing, cooling water for thermal control loops, and oxygen for atmospheric revitalization. In addition, water and oxygen are also needed in portable life support systems for extravehicular activities for heat rejection and breathing. Some gaseous nitrogen will be needed for atmospheric pressure control. Until fully closed loop life support systems can be developed, there will be a need for resupply of these critical commodities. Some estimates for total quantities of these consumables for lunar bases are substantial (ref) and an orbital consumable depots that supplies these consumables is needed.

Pressurization - Currently, gaseous helium is used as a pressurant for spacecraft propulsion tanks as well as pneumatics for various actuations. On the ground however, typical cryogenic operations use autogenous pressurization via vaporizers to provide necessary pressure for fluid transfer. Autogenous pressurization is used for pressurization of hydrogen tanks during operation, but helium is used for liquid oxygen tanks. However helium pressurization adds complexity, especially in reusable systems where multispecies mixtures may not be desirable.

\subsection{Reusability}

Another key operability principal is maximum reusability of assets in space. This will help minimize overall mission mass. A simple example of this concept is reusability of the upper stage propulsion system as an earth departure stage (EDS) after reservicing by in-space consumable stations. While there are still benefits to using an upper stage to deploy an empty EDS on orbit, and then filling the EDS using a consumable depot after the upper stage has been discarded, there is a considerably higher benefit to reusing the upper stage as an EDS after refueling. This allows for elimination of the dry mass of the EDS from the payload mass of the upper stage and maximizes the true payload mass to be delivered. This also simplifies the servicing of the cryogenic tanks, as reservicing a cold tank does not require chill down of large quantities of mass to cold temperatures like servicing a warm talk would.

Taking this concept to the limits of practicality, mass should be distributed in the system to the location where it can utilize the concept of reusability to its maximum extent. This means all systems necessary for operation of a depot should reside on the depot where practical. Active components of docking systems should be placed on the depot side of the interface so the spacecraft docking plates can be made simpler and less massive. If possible, active thermal control systems should remain with the depot as well, unless it is absolutely necessary to include them on the spacecraft.

\subsection{Design for the Environment}

Current cryogenic propulsion stages are loaded using fluid stored at or near the normal boiling point (NBP) on the ground. Prior to use, the fluid is subcooled by pressurizing with gaseous helium. This subcooling is necessary for operation of the engine turbomachinery, but does little to increase the storage density of the fluid. Over the years, there have been numerous proposals to use densified propellants, or propellants that are cooled to below their NBP temperature. The decrease in temperature is accompanied by an increase in fluid density, allowing for greater mass of propellant to be stored in a given volume. While densification will help increase the payload mass fraction, there are operational impacts associated with use on earth and there have been no known vehicles that have used both densified hydrogen and oxygen as propellants. However, in space propulsion stages experience different surroundings than Earth based stages, specifically the presence of vacuum. This begs the question, what is the normal boiling point of fluids in space? With no atmospheric backpressure to limit the venting, cryogens can be stored well below their "NBP" and storage at the triple point or below is achieveable. However there are engineering challenges associated with slush cryogens and the preferred state of normal storage is assumed to be saturated liquid at $16 \mathrm{~K}$ for hydrogen and $65 \mathrm{~K}$ for oxygen. This storage condition increases the density of LH2 by $6 \%$ over NBP hydrogen, and $10 \%$ over the NBP of liquid oxygen. Vehicles that are intended to operate exclusively in space should be designed to take advantage of the unique space boundary conditions, and lowering the storage temperature to increase fluid density is a feasible method of minimizing spacecraft volumes and masses.

The surroundings of a cryogenic system in space is very different than on Earth.. The main difference is the presence of high vacuum, eliminating the need for a vacuum jacket. This also has an effect on the effective surroundings of the thermodynamic system. On earth, the surroundings generally are assumed to form a warm boundary temperature of $300 \mathrm{~K}$. However, proper design of outer insulation layers and their material properties have demonstrated that warm boundary temperatures of 220K are achievable in LEO (ref). This affects the cryogenic system in two ways. First, heat leak will be reduced as the temperature gradient across the insulation will be smaller. Second, the coefficient of performance of the refrigerator system will be increased. The corresponding decrease in cryocooler power will decrease the mass of the system, but the penalty is increased mass of the radiator due to the lower temperature. Table XX shows the effect of lowering the heat sink temperature on the COP of an ideal refrigeration system that has a source temperature of $20 \mathrm{~K}$ or $15 \mathrm{~K}$. The secondary $\mathrm{y}$-axis shows the mass trade. 


\subsection{Active Control of Propellants}

The potential key to cryogenic fluid management in space is to maintain active control of the propellant. Active control means control of both the state of the cryogen (active thermal control) as well as the position of the fluid in the tank (active fluid control). In this work, the word control is taken to mean; "to exercise directing influence over, to have power over". Used in this context there is no such thing as passive thermal control and concepts for "reduced boil off" (RBO) using active thermal control is a misnomer. There is no effective control if all one can do is minimize the effect of heat leak, because the state of the propellant is being controlled by external forces, not the active or passive systems in the spacecraft. To have true control, one must be able to regulate or govern the state of the propellant, including decreasing the bulk fluid temperature or system pressure when desired. To have true active thermal control in these cases, the ratio of the provided refrigeration power to the vessel heat leak must be greater than 1.

$$
\frac{Q_{\text {ref }}}{Q_{H L}}>1
$$

Active thermal control has been the topic of many thermal analysis exercises recently. In these cases, active thermal control is typically restricted near the point of zero boil off $(\mathrm{ZBO})$, where refrigeration is provided to maintain the cryogen at steady state. Current NASA plans for in space cryogenic demonstrations with liquid oxygen are considering refrigeration ratios slightly higher than 1 , to account for transient heating during ascent and to maintain some level of pressure control. Plans for LH2 are reduced boil off, where the refrigerator intercepts around $80 \%$ of the heat leak using a shield at an intermediate temperature. However, more than just zero boil off is possible with a focused effort to develop larger capacity staged refrigeration systems like the Claude cycles used in hydrogen liquefiers on Earth.

Active fluid control means the spacecraft has the ability to control the position of the fluid in the tank. Used in this context Propellant settling maneuvers is considered active fluid control. But a better example is a tank mixing pump with a spray bar, although it depends on a passive liquid acquisition device to provide liquid to the pump inlet. The pump with the discharge nozzles are capable of directing liquid to a desired location in order to achieve isothermal conditions desired for better thermal and pressure control. But with proper design, the pump mass flow can be used to help maintain liquid position as well. For example, a tangential velocity relative to the tank wall can create centrifugal forces to hold the liquid to the outer wall while vapor concentrates down the axis. Or diffusers can inject the liquid axially down the tank to accumulate at the liquid acquisition device. Active fluid control can use a mechanical phase separator system, especially in a liquefier system. Turbulators built into injectors may be able to separate the liquid or centrifugal pumps like the space shuttle humidity separators can be use. Finally, magnetic forces can be used, especially for LOX, to actively control the position of the fluid.

\section{PROPOSED DEPOT ARCHITECTURE}

Using the principles outlined above, a proposed depot architecture will now be presented. The depot is based on the concept of simplifying launch operations by launching water on an as needed basis to facility that can electrolyze the water and liquefy hydrogen and oxygen product for storage in the customers spacecraft propellant tanks. The facility also has the capability to supply pressurized oxygen and hydrogen gas as well as water to the customer. An Excel based model of the system thermodynamics has been developed and a schematic of the proposed system is shown in Figure 1.

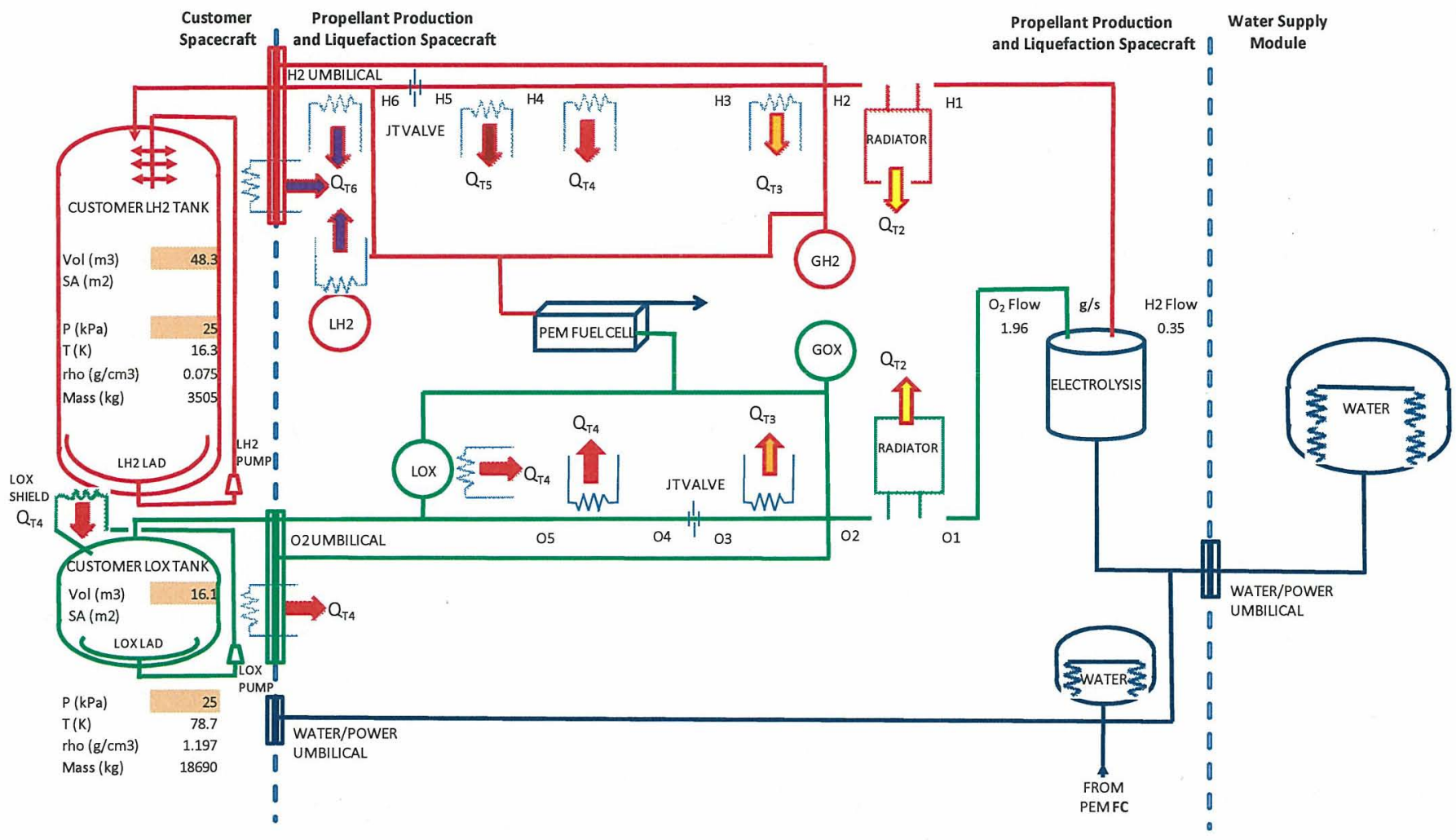




\subsection{Water supply modules}

The depot facility is only supplied with the feedstock of high purity water. This offers many advantages. Water storage is simple compared to a LOX and LH2. Water launch does not need a vacuum jacket or efficient insulation systems. Water is easier to store near thermal equilibrium, especially during ground and launch phases of operations. Water is a volumetrically efficient method of storing hydrogen and oxygen. INSERT QUANTIFIED DATA HERE. These factors lead to a much higher payload mass fraction for the resupply portions of the operations. This helps minimize the repetitive launch costs that form a large fraction of the depot cost structure, making the depot more attractive from a commercial standpoint. Launchs site will not require LH2 ground support equipment, and water is a simple payload to process.

The water supply modules should be as simple as possible. They can be mass produced for economy of scale. In order to maximize reusability and minimize single-use systems, all the active components for rendezvous and docking should reside on the depot side. The water supply module should have minimum capability for attitude control, communication, and power supply.

\subsection{Depot Spacecraft}

The depot spacecraft is the key component of the system. It is a multifunctional spacecraft that includes all command and control systems, propulsion for orbital maneuvering, attitude control, and docking operations, a remote manipulator system, power supply and distribution network, and thermal control systems. The depot spacecraft's primary purpose is to receive water from the WSM, electrolyze it at high pressure, and liquefy the oxygen and hydrogen output streams. The LOX and LH2 is then transferred to fill the empty storage tanks on the customer spacecraft. The depot has the capability to transfer liquid water, gaseous hydrogen and oxygen, and liquid hydrogen and oxygen. The depot also provides refrigeration to the customer spacecraft while they are docked. Further explanations of the key payload systems are provided next.

Water Electrolysis - Water is split into hydrogen and oxygen via the electrolysis process. The electrolysis system consists of the electrolysis stack, probably a proton exchange membrane system, the gaseous purification process to ensure the product is ready for liquefaction, and the associated fluids and electrical controls components. The process is well understood and the engineering is mature. There is an electrolyzer of the International Space Station (ISS) and has displayed good reliability. It is capable of producing $\mathrm{x} \mathrm{g} / \mathrm{s}$ of hydrogen and $\mathrm{xg} / \mathrm{s}$ of oxygen and the specific power is roughly $\mathrm{xx} \mathrm{j} / \mathrm{g}$. While this unit is too small for the depot purpose, the US Navy has extensive experience using larger electrolysis units for submarines. Several companies manufacture the units including Treadwell, Hamilton Sunstrand, and Giner with oxygen flow capacity greater than $2 \mathrm{~g} / \mathrm{s}$. Specific power ranges from 50 to $60 \mathrm{j} / \mathrm{g}$. Another advantage of the US Navy electrolysis development is high output pressures can be achieved for minimal power increase. Oxygen pressures up to $20 \mathrm{MPa}$ and hydrogen pressure up to $5.2 \mathrm{MPa}$ have been demonstrated. This minimizes the liquefication energy required. However water electrolysis is still a very energy intensive process and drives the size of the spacecraft power systems. The system model that was created uses electrolysis efficiencies, flow capacity, and outlet pressures as input variables.

Power Generation - While future depot spacecraft will leverage off development of space based nuclear power, the initial models will need to rely on solar power. Due to the large amount of energy required by the electrolysis and liquefaction/refrigeration system, very large solar arrays will be needed. The model estimates maximum power required by considering total LH2 and LO2 produced and liquefied over a range of possible time durations. The estimated solar array area and mass are calculated using parametric relations (ref). The power generation system includes the main solar arrays and solar tracking components, power conditioning and distribution units, and a regenerative fuel cell that provides backup power during periods of eclipse or other off nominal operations. Similar to the ISS solar array wings, needs multiple arms each of the depot solar arms are $34 \mathrm{~m}$ long by $12 \mathrm{~m}$ wide, and are capable of generating nearly $32.8 \mathrm{~kW}$ of DC power. Total System mass is $4400 \mathrm{~kg}$.

Active Thermal Control - Refrigerator - There are many possible cycles that can be used to liquefy the gaseous product from the electrolyzer. The spacecraft model considers two main alternatives to liquefaction. The first is a closed cycle Brayton refrigeration system that is designed to remove heat from the product stream in a series of stages, finalizing in a cold stage temperature a few degrees colder than the desired storage temperature. This is the type of system shown in Figure 1. Following the hydrogen product stream out of the electrolysis unit, the hydrogen is first precooled in a radiator passively to a desired temperature. Next, a series of heat exchangers further pre-cools the gas using a multi-stage Brayton refrigerator. This refrigerator also cools the oxygen stream using the same temperature expansion stages. After the hydrogen is cooled to below $40 \mathrm{~K}$, a Joule-Thompson (JT) valve expands the gas isenthalpically into a two phase fluid. The refrigerator then provides the additional cooling necessary to liquefy the remaining saturated vapor prior to being delivered to the customer spacecraft in an expanded metal foam condensing heat exchanger. The depot provides refrigeration to the spacecraft customer for full propellant conditioning for the duration the two are docked. This allows all the necessary refrigeration equipment to remain on the depot to be continuously reused, and no cryocoolers will be necessary for individual customer spacecraft.

The system model uses input variables for mass flow rate, inlet pressure, and refrigeration efficiency. Thermodynamic state variables are calculated for a series of processes. Optimum radiator temperatures are calculated based on mass trades against the refrigerator power mass. The heat exchangers are modeled as an isobaric process with ideal heat exchanger. This gives the refrigeration capacity required at each stage. An isenthalpic expansion reduces the propellant pressure to just above the desired storage pressure. The refrigeration required to remove the remaining latent heat is added to the refrigeration required to remove all system parasitic to find the final capacity at the storage temperature. Once all the refrigeration heat sources are added together, taking into account each stages coefficient of performance and the overall cycle efficiency, a required input power can be estimated. Individual stage temperatures are then optimized for minimum input power for given hydrogen storage temperature, radiator 
temperature, and gas pressure. The temperature of the fourth thermal station (around LOX temperatures) is then set by this refrigeration efficiency analysis, which dictates the LOX storage temperature. Figure 2 below displays the system model output for a representative mission.

\begin{tabular}{|c|c|c|c|c|c|c|c|c|c|}
\hline & $\begin{array}{l}\mathrm{T} \\
\mathrm{K} \\
\end{array}$ & $\begin{array}{c}\mathrm{P} \\
\mathrm{kPa}\end{array}$ & $\begin{array}{c}\text { rho } \\
\mathrm{g} / \mathrm{cm} 3\end{array}$ & $\begin{array}{c}\mathrm{h} \\
\mathrm{J} / \mathrm{g}\end{array}$ & $\begin{array}{c}s \\
J / g-K \\
\end{array}$ & $\begin{array}{c}\text { Qliq } \\
\text { W }\end{array}$ & $\begin{array}{l}\text { Qhl } \\
\text { W }\end{array}$ & COP & $\begin{array}{c}\text { Power } \\
\text { W }\end{array}$ \\
\hline 01 & 300 & 5050 & 0.07 & 261.0 & 5.365 & & & & \\
\hline $\mathrm{O} 2$ & 240 & 5050 & 0.09 & 199.2 & 5.134 & 65 & & & \\
\hline $\mathrm{O3}$ & 138.4 & 5050 & 0.86 & -42.3 & 3.699 & 253 & & 0.86 & 1073 \\
\hline 04 & 78.7 & 25 & 0.00 & -42.3 & 5.552 & & & & \\
\hline 05 & 78.7 & 25 & 1.20 & -152.6 & 5.552 & 115 & 144 & 0.36 & 2654 \\
\hline & & & & & & & & O2 TOTAL & 3727 \\
\hline $\mathrm{H} 1$ & 300 & 5050 & 0.004 & 4226 & 48.566 & & & & \\
\hline $\mathrm{H} 2$ & 240 & 5050 & 0.005 & 3366 & 45.368 & 161 & & & \\
\hline H3 & 138.4 & 5050 & 0.009 & 1950 & 37.738 & 264 & & 0.86 & 1123 \\
\hline $\mathrm{H} 4$ & 78.7 & 5050 & 0.016 & 1038 & 29.003 & 170 & & 0.36 & 1742 \\
\hline H5 & 36.5 & 5050 & 0.058 & 13 & 9.849 & 191 & & 0.14 & 5025 \\
\hline H6 & 16.3 & 25 & 0.075 & 13 & 0.374 & & & & \\
\hline $\mathrm{H} 7$ & 16.3 & 25 & 0.075 & -316 & 0.374 & 62 & 38 & 0.06 & 6284 \\
\hline & 12 flow & \multicolumn{2}{|c|}{$0.19 \mathrm{~g} / \mathrm{s}$} & & & fficiency & 0.275 & H2 TOTAL & 14174 \\
\hline & 2 flow & \multicolumn{2}{|c|}{$1.05 \mathrm{~g} / \mathrm{s}$} & & & & & TOTAL & 17901 \\
\hline
\end{tabular}

Figure 2) Refrigeration Capacity at Temperature and Required Input Power

Active thermal control - Liquefier - Instead of using a closed-cycle refrigeration system to liquefy the gas, a more conventiaonal open cycle liquefier can be employed Figure xx shows a rough schematic of one such system. In this case, product gas is provided from the electrolyzer ate high pressure as a make-up gas to the cycle. The oxygen is liquefied using a relatively simple Linde-Hampson cycle, pre-cooled by the radiator to below 250K. After the final expansion stage, two phase fluid is sent to the storage tank, either on board the depot or on the customer spacecraft. For liquid oxygen, phase separation is achieved using a magnetic settling system, and the return vapor is sent to the liquefier compressor to complete the cycle. The liquid hydrogen follows a similar cycle, being precooled first by a radiator and then by the oxygen cycle, prior to several stages of expansion itself. Again, the two phase fluid is separated in the storage tank, this time using either liquid acquisition devices or an active centrifugal separator. A recuperative heat exchanger is used to recover any latent heat of vaporization present in the return vapor stream in the event some small amount of liquid enters the return line.

Storage and distribution - The storage and distribution system includes all the components necessary to control the position of the fluid in the system, including lines, valves, instrumentation, and storage. The primary storage tanks are the customers tanks, still cold from the orbital insertion phase of their mission but drained to their residual point. When A customer is not docked at the depot, there is secondary storage on board the depot to allow the refrigeration system to maintain operations, to provide for H2/Os2 storage for depot systems such as OMS/RCS, and to provide energy storage for the fuel cells. The depot has both $\mathrm{GH} 2 / \mathrm{GO} 2$ and $\mathrm{LH} 2 / \mathrm{LO} 2$ storage, as well as water.

Umbilicals- The active components of the docking systems reside on the depot sides of the interfaces. The depot has a simple umbilical interface with the WSM, with water and power disconnects only. Heaters serve as active thermal control to keep the water above freezing. The mating capture and alignment is performed by a remote manipualor arm on the depot, while actuation force for the umbilical plate is supplied by the active mechanism on the depot side.

Propulsion - The depot has the capability for orbital maneuvering and reaction control. The customer spacecraft will have the responsibility to attain a nearby orbit and the depot will have the responsibility to perform the necessary maneuvers to bring the three spacecraft together. Both the OMS engines and the RCS thrusters use hydrogen and oxygen as propellants. The OMS engines may use liquid similar to a scaled version of the RL-10 and the RCS thrusters will probably use gas.

Thermal Insulation systems - The depot spacecraft will use an integrated thermal insulation system designed to minimize parasitic loads on the refrigerator. The depot will use a heat stationing approach where warm components are located together at one end of the spacecraft and the progressively colder stages are positioned to take maximum advantage of the shielding (and active cooling) of the higher temperature stations. All penetrations between stations will use low conductivity supports and feedthrus where possible. Deployed solar shields may be used to protect against radiation, or the large solar arrays can be designed to fill that role. Since the depot is launched dry and refrigeration is not activated until orbital insertion, there is no need for hybrid insulation to protect systems during ground processing or ascent phases of the mission. The spacecraft design should be optimized for use only at its intended location, in LEO. Since the capacity of the active thermal control system is many times larger than the typical parasitic heat leak of the depot stage, there are no attitude constraints on the spacecraft thermal system when the depot is not in liquefaction mode.

\subsection{Customer Spacecraft}

A number of different customers could use such a depot. A typical customer is a refueling of an upper stage to serve as an earth departure stage for lunar or planetary missions. In this case, the upper stage arrives with propellant tanks near empty but still cold. The depot initiates the docking and connection of umbilicals and then starts filling the customer tanks. All customers will be required to have standard umbilical interfaces for water, gaseous oxygen and gaseous hydrogen, and liquid oxygen and liquid hydrogen transfer 
The exact umbilical connection will change depending on the type of liquefier used in the depot. Refrigeration is provided in a separate umbilical if that thermal control scheme is used. The customer will have to integrate refueling specific hardware in its systems, such as spray bars, mixing pumps, enhanced insulation, and thermal shields. The depot controls the attitude of the system while docked to maintain maximum solar power.

The functions of these individual spacecraft and their associated systems will now be demonstrated in a consideration of a typical mission concept of operations.

\section{CONCEPT OF OPERATIONS}

To demonstrate the capability of this depot architecture, a representative concept of operations will be presented. This will include the initial depot launch and activation, a nominal water resupply, and servicing of a projected customer. A centaur refueling for an interplanetary science mission is the customer.

First, the depot spacecraft will be launched to the designated orbit by a launch vehicle. The depot is a payload that is launched with minimal consumable mass on board, just enough to pass a functional checkout and enter stable operational mode on orbit. The depot water tank is filled to $10 \%$ with water. The depot water tanks are pressurized with gaseous nitrogen using a bellows like bladder similar to the space shuttle water tanks. The depot GOX and GH2 tanks are pressurized to maximum allowable working pressure to provide propellant for the OMS/RCS systems, as well as back-up power reactants to the regenerative fuel cell system. The LH2 and LOX tanks are filled to a minimal level necessary to start the system on orbit. The spacecraft is launched powered down, and is activated upon being delivered to the intended orbit. Once in orbit, the spacecraft is powered up by starting the PEM fuel cell, with the product water being sent to the depot water tank. The depot then establishes communication and control with the ground stations and the OMS/RCS system is checked out. Next, the solar arrays are deployed to the correct orientation. After full power is available the propellant production and liquefaction system can be activated.

To activate the PPLS, The refrigerator is started and allowed to chill down. Chill down of the $\mathrm{H} 2$ and $\mathrm{O} 2$ transfer system can be helped by liquid in the storage tanks. Water from the depot water tank is then sent to the electrolyzer, and the electrolysis system produces hydrogen and oxygen at a pressure of $5000 \mathrm{kPa}$. This charges the high pressure line and the cold, high pressure gas is expanded and liquefied in the condensing heat exchanger. The system is now in stable operational mode with power produced by the fuel cell used to run the electrolyzer. The solar arrays provide the power for refrigeration for liquefaction plus maintaining thermal equilibrium, as well as make up power for the electrolysis/fuel cell cycle and spacecraft operations. The depot is now ready to receive water.

The concept of operations is simple for the water launch. A water supply module is launched using an expandable launch vehicle and sent to an orbit near the depot. The WSM processing is very simple and payload is very mass and volumetrically efficient. The WSM has the capability for 1 week in orbit prior to rendezvous with the depot. One the depot acquires the WSM, the water umbilical is mated and large scale propellant production and liquefaction is ready to start.

The customer spacecraft then arrives. A range of possible refueling options exist but consider the upper stage arrives near empty but cold. The customer is required to rendezvous within $\mathrm{xx}$ delta $\mathrm{V}$ of the depot and then the depot actively mates with the customer spacecraft. In the event of refrigerator active thermal control the cooling service is connected and chilled down. Then the spacecraft mixing pump is activated, establishing steady operation with the refrigerator. The liquid supply ports are then opened, routing the propellant from the depot cycle to the customer tanks. The two spacecraft remain together until the desired amount of propellants is transferred. This is period could last six months or more, depending on the depot power level and the customer tank size.

\section{SUMMARY}

A summary of operability principles is used to develop a reference concept architecture for a propellant depot in low earth orbit. The architecture is based on large scale active control of the propellants similar to hydrogen production and liquefaction plants on earth. Components include water supply modules, a depot spacecraft with solar power, a electrolysis and fuel cell cycle, refrigeration/liquefaction system, and storage and transfer systems, and a variety of customer spacecraft including earth departure stages, orbital transfer vehicles, and manned spacecraft. First order system size and mass estimates for the depot are analyzed. A concept of operations is included.

\section{REFERENCES}

\begin{tabular}{|l|c|c|c|}
\hline \multirow{2}{*}{ Vehicle volume } & LH2 & & LOX \\
\cline { 2 - 4 } & 10210.4 & $\mathrm{gal}$ & 3411.2 \\
\hline Bulk Storage temp & 38.7 & $\mathrm{~m} 3$ & 12.9 \\
\hline Storage Pressure & 16 & $\mathrm{~K}$ & 65 \\
\hline Storage Density & 3.5 & $\mathrm{psi}$ & 3.5 \\
\hline Storage Mass & 24 & $\mathrm{kPa}$ & 24 \\
\hline & 0.075119 & $\mathrm{~g} / \mathrm{cm} 3$ & 1.259715 \\
\hline Liquefaction time & 75.12 & $\mathrm{~kg} / \mathrm{m} 3$ & 1259.72 \\
\hline Liquefaction rate & 2903 & $\mathrm{~kg}$ & 16266 \\
\hline & 0.151 & $\%$ & 0.849 \\
\hline Ideal energy of Liq & 180 & $\mathrm{days}$ & 180 \\
\hline Efficiency & 12019 & $\mathrm{GPD}$ & 19 \\
\hline Liquefaction power & 11.2 & $\mathrm{~kJ} / \mathrm{kg}$ & 635.6 \\
\hline Refrigeration power & 14 & $\mathrm{~kW}$ & 2.4 \\
\hline & & & \\
\hline Electrolysis energy & 50 & $\mathrm{~kW}-\mathrm{hr} / \mathrm{kg}$ & \\
\hline Electrolysis power & 34 & $\mathrm{~kW}$ & \\
\hline Total Power Input & 52 & & \\
\hline
\end{tabular}




\title{
Active Control of Cryogenic Propellants in Space
}

\author{
William Notardonato, Ph.D. \\ Cryogenic Test Laboratory NE-F6 \\ Engineering and Technology Directorate \\ NASA Kennedy Space Center
}




\section{Outline}

- Cryogenic propellant depots

- Architecture benefits

- Technical challenges

- Design for operability

- Design principles

- Commonality

- Design to space environment

- Reusability

- Active Control of Propellants

- Proposed Depot Architecture

- Water Supply Module

- Depot Spacecraft

- Customer Spacecraft

- Concept of Operations 


\section{Design Principles}

- Commonality

- Keep the spacecraft simple by minimizing the number of different fluids that need to be supplied

- Use of water, hydrogen and oxygen only

- GOX/GH2 engines and thrusters for OMS/RCS

- Hydrogen and oxygen for regenerative fuel cell power

- Water and oxygen for life support systems, including cooling and heat rejection

- Water and oxygen for EVA

- Autogenous pressurization, no helium

- Single species

- Design to the environment

- Propellant state

- Propellant densification and subcooling

- What is NBP in space

- Lower temperature surroundings

- Insulation systems 


\section{Design Principles}

- Reusability

- Reuse of upper stage as EDS

- Already cold

- Maximum reusability

- All functionality on depot

- Active Control of propellant

- Active thermal control

- Active vs passive

- Refrigeration ratio and ZBO

- Large scale distributed cooling systems

- Use of shields

- Isothermal

- Active fluid control

- Settling

- Mixing pump with LAD

- Phase separators

- Magnetic settling 


\section{Proposed depot architecture}

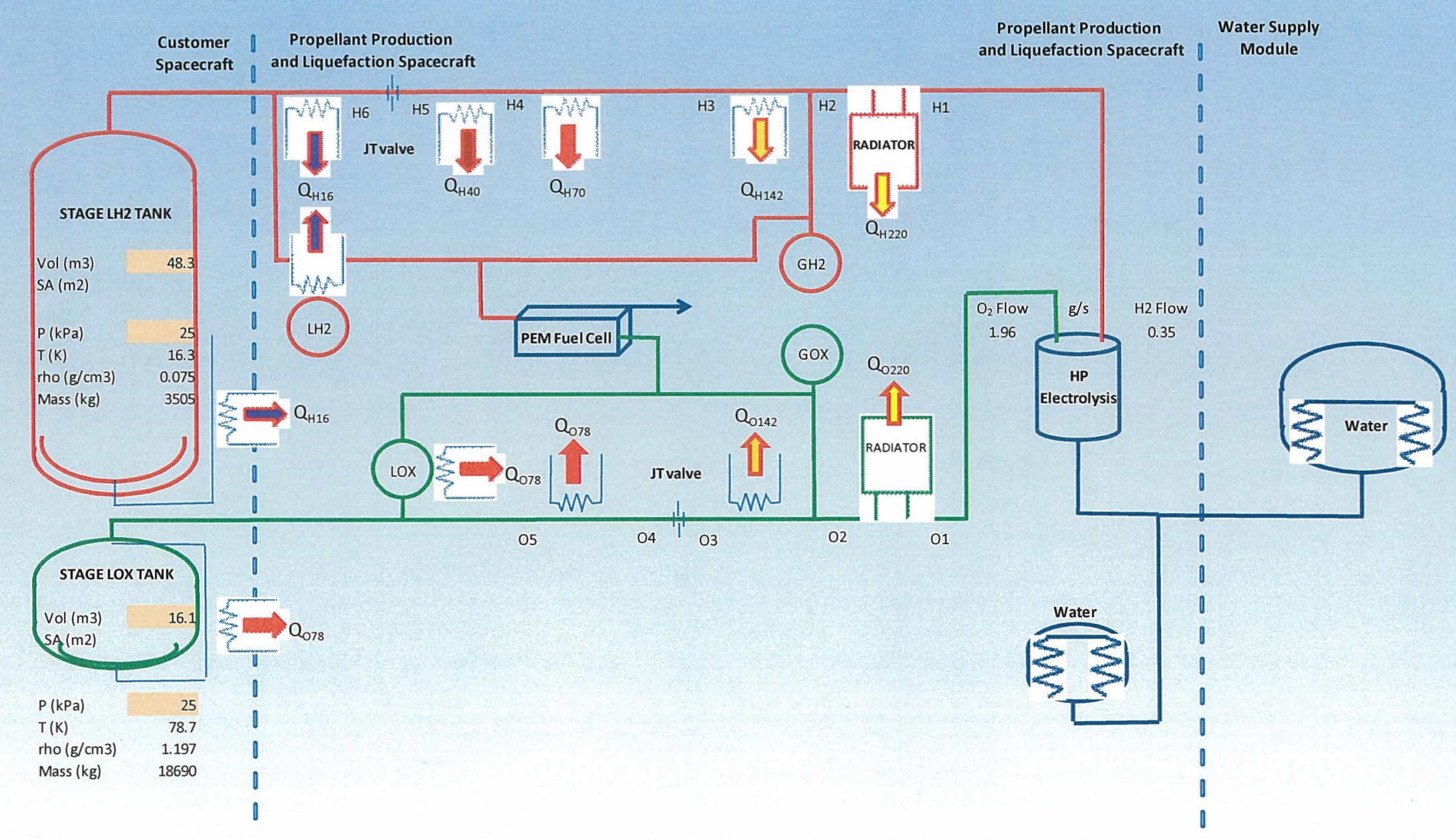




\section{Depot Spacecraft}

- Water Electrolysis

- US Navy heritage

- 50-60 kW-hr/kg

- High pressure gas outlet for liquefaction

- Solar power with regenerative fuel cell back-up

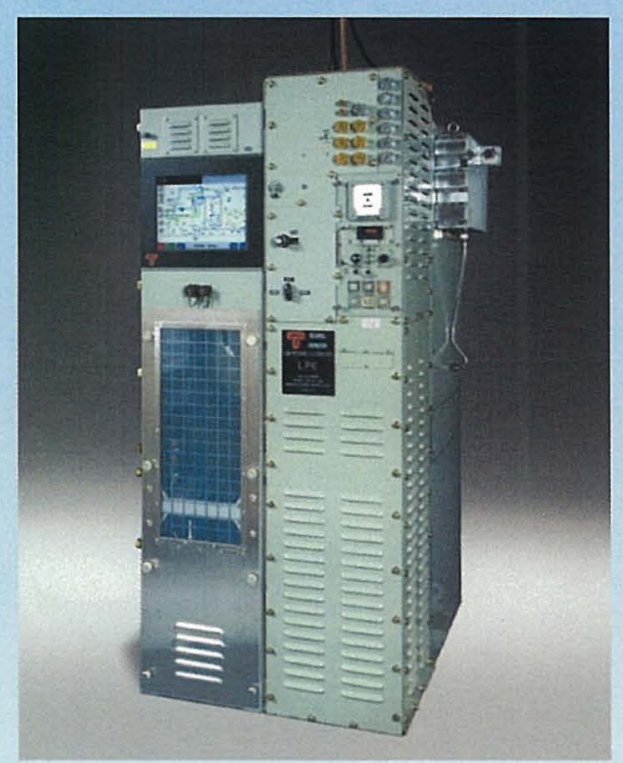

- Water, GH2, GOX, LH2, LOX storage and transfer

- Provides thermal conditioning 


\section{Depot Spacecraft}

- Active Propellant Control System

- Propellant precooled by radiator and refrigeration heat exchangers

- High capacity multistage refrigerator for precooling propellant

- Joule thompson expansion for initial liquefaction

- Refrigeration for final

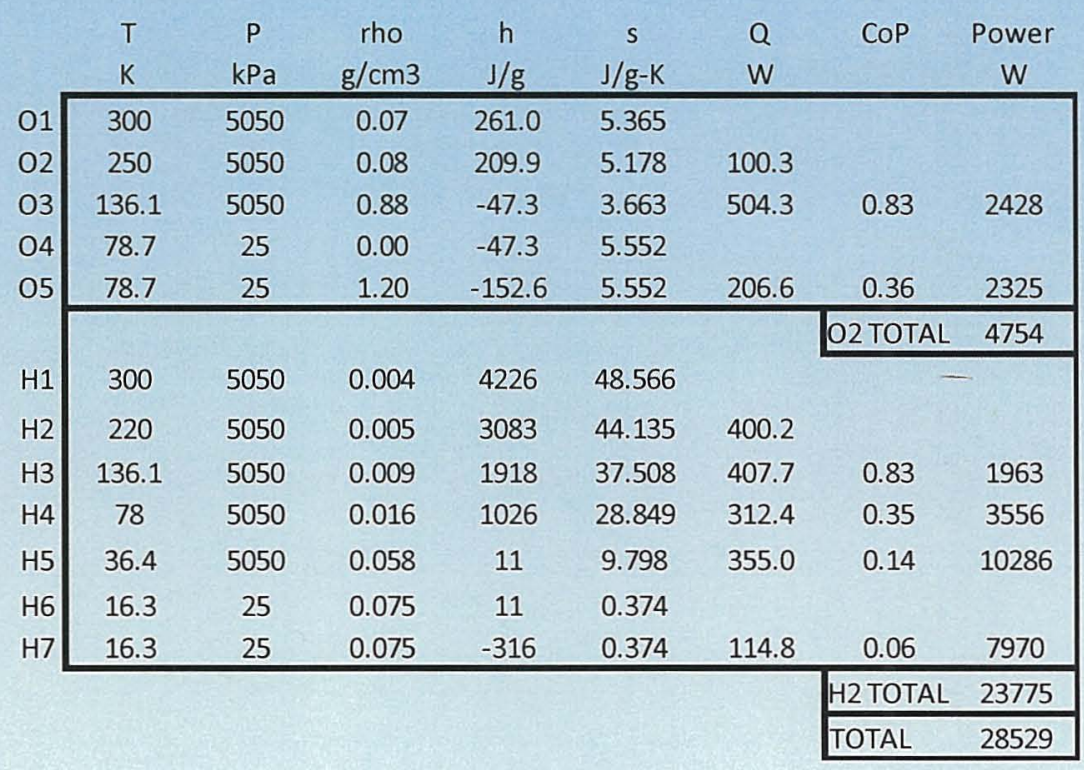
liquefaction and liquid conditioning

- Active fluid control using spray bars and nozzles, liquid acquisition devices and mixing pumps 


\section{Concept of Operations}
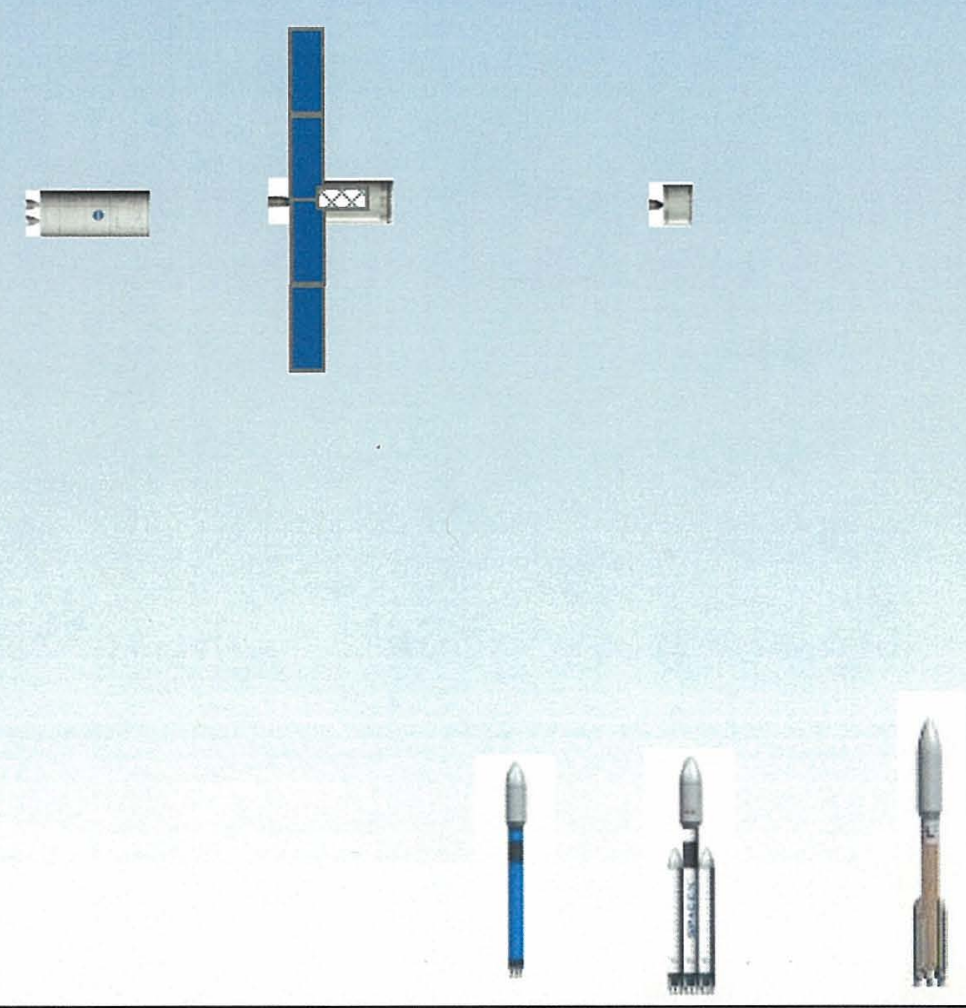


\section{Depot Sizing}

- Depends on time scale

- Limited by solar power

- Centaur scale tanks in 4 to 6 months

- Refrigerator and electrolysis

\begin{tabular}{|c|c|c|c|}
\hline & LH2 & & LOX \\
\hline \multirow[t]{2}{*}{ Vehicle volume } & 10018 & gal & 3347 \\
\hline & 37.9 & m3 & 12.7 \\
\hline \multirow[t]{2}{*}{ Bulk Storage temp } & & $\mathrm{R}$ & \\
\hline & 16 & K & 65 \\
\hline \multirow[t]{2}{*}{ Storage Pressure } & 3.5 & psi & 3.5 \\
\hline & 24 & $\mathrm{kPa}$ & 24 \\
\hline \multirow[t]{2}{*}{ Storage Density } & 0.075 & $\mathrm{~g} / \mathrm{cm} 3$ & 1.26 \\
\hline & 75.1 & $\mathrm{~kg} / \mathrm{m} 3$ & 1260 \\
\hline \multirow[t]{2}{*}{ Storage Mass } & 2849 & $\mathrm{~kg}$ & 15960 \\
\hline & 0.151 & $\%$ & 0.849 \\
\hline \multirow[t]{2}{*}{ Liquefaction time } & 180 & days & 180 \\
\hline & & seconds & \\
\hline \multirow[t]{3}{*}{ Liquefaction rate } & 56 & GPD & 19 \\
\hline & 16 & $\mathrm{~kg} /$ day & 89 \\
\hline & 0.183 & $\mathrm{~g} / \mathrm{s}$ & 1.03 \\
\hline Ideal energy of Liq & 12019 & $\mathrm{~kJ} / \mathrm{kg}$ & 635.6 \\
\hline Efficiency & 0.2 & & 0.2 \\
\hline \multirow[t]{2}{*}{ Liquefaction power } & 11.0 & kW & 3.3 \\
\hline & & & \\
\hline Energy of electrolysis & 50 & $\mathrm{~kW}-\mathrm{hr} / \mathrm{kg}$ & \\
\hline Electrolysis power & 33 & kW & \\
\hline Total power & 47.2 & $\mathrm{~kW}$ & \\
\hline
\end{tabular}

